\title{
Research on the Talent Demand of Cross-border E- Commerce under the Belt and Road Initiative
}

\author{
Yijing Huang* \\ Jiangsu Maritime Vocational Institute, Nanjing 211199, Jiangsu Province, China \\ *Corresponding author: Yijing Huang, huangchenyijing@163.com
}

\begin{abstract}
With the industrial upgrading and the proposal of the Belt and Road Initiative, the cross-border e-commerce industry has developed rapidly. Its dominance in the whole import and export industry has been continuously strengthened, leading to the increasing demand for cross-border e-commerce talents. As the main place for training cross-border e-commerce talents, colleges and universities are far from the needs of the industry in their training of these talents. Therefore, this article analyzes the demand for cross-border e-commerce talents through research, interviews, and data sorting, as well as provides several suggestions for the training of cross-border e-commerce talents in colleges and universities.
\end{abstract}

Keywords: Belt and Road Initiative; Cross-border e-commerce; Talent demand

Publication date: June 2021; Online publication: June 30, 2021

\section{Introduction}

With the proposal of the Belt and Road Initiative, cross-border e-commerce has become a new growth point of the import and export trade. According to the data in 2020, the scale of cross-border e-commerce transactions has reached 12.5 trillion yuan. It is expected that the compound growth rate of China's crossborder e-commerce market would reach $25 \%$ from 2020 to 2025. This series of data implies that the dominance of cross-border e-commerce in the whole import and export trade industry would continue to strengthen. The explosive growth of the industry has spawned a strong demand for cross-border ecommerce professionals. Although majority of the universities are actively exploring the mode of training for these talents, there is still a serious shortage of cross-border e-commerce talents. At present, China's cross-border e-commerce talent gap exceeds 6 million and is still expanding at an annual growth rate of $30 \%$.

\section{Analysis on the demand for cross-border e-commerce talents}

\subsection{Structure of talent demand}

The structure of talent demand by cross-border e-commerce enterprises mainly includes three types of cross-border talents: business talents, management talents, and technical talents. Business talents include customer service specialist, marketing promoter, store operator, and warehouse keeper; management talents include operation director, business planning director, logistics director, procurement and supply chain director, as well as international settlement finance director; technical talents include product research and development specialist and art designer. 


\subsection{Recruitment preference of cross-border e-commerce enterprises}

Data have shown that cross-border e-commerce enterprises have the strongest market demand for skilled talents in sales and marketing promotion, data operation, customer management, and product selection analysis. In terms of professional preference, they are more inclined to recruit students with a major in International Trade, E-Commerce, or Business English. In terms of personality, enterprises are looking for employees with enterprising spirit, strong learning ability, initiative, and have certain independence. In terms of experience, $77 \%$ of enterprises prefer to recruit those who have one to three years of working experience; only $23 \%$ of enterprises would recruit fresh graduates. When recruiting fresh graduates, most cross-border enterprises do not oppose the recruitment of junior college students; however, the lowest educational threshold for them is those from junior college.

\subsection{Posts for fresh college graduates offered by cross-border e-commerce enterprises}

\subsubsection{Customer service}

Job responsibilities (1) Pre-sales customer service handles customer inquiries and guides transactions.

(2) During sales, the customer service determines the order quantity, color, model series, specification, size, payment, etc., and carries out logistics tracking, delivery, and after-sales maintenance according to the customer order information.

(3) After-sales customer service handles after-sales issues.

(4) Customer relationship maintenance (old customer and after-sales return visit).

(5) Achieve a specified sales target.

Job requirements (1) CET-4 or above; ability to communicate in English or other languages.

(2) Master platform rules, products, and standard scripts.

(3) Have a certain understanding of third-party operation platform, and be able to communicate with customers through e-mail, instant messaging, as well as other communication channels.

(4) Understand the process of cross-border e-commerce.

(5) Have business negotiation skills, strong public relations awareness, and strong dedication.

Assessment index Sales target, inquiry conversion rate, customer unit price, first question response time, average response time, response rate, question answering ratio, proportion of withdrawal amount, service attitude, work enthusiasm, sense of responsibility, praises from customers, customers' complaints, violation of platform rules, etc.

\subsubsection{Network promotion}

Job responsibilities (1) Paid promotion, competitive ranking, and network alliance cooperation.

(2) Promotion outside the station: Responsible for the promotion of social platform and brand promotion via Facebook, Skype, etc.

(3) Formulate promotion plans and complete promotional activities.

Job requirements (1) CET-4 or above; ability to communicate in English or other languages.

(2) Familiar with search engine optimization, link exchange, website optimization, other technologies and data analysis methods to promote commodities.

(3) Understand the thinking mode and lifestyle of overseas consumers; able to use network marketing means to promote goods.

Assessment index Promotion sales, return on investment, page view, unique visitors, click through rate, conversion rate, etc. 


\subsubsection{Visual design}
Job responsibilities
(1) Shop decoration, detailed page production, and uploading contents
(2) Product shooting, video and picture processing, beautification, etc.
(3) Visual marketing and product activity marketing design.
(4) Page optimization to promote transformation.
Job requirements (1) CET-4 or above; better with mastering other languages.
(2) Familiar with Photoshop, Dreamweaver, video editing, and other software operations.
(3) Proficient in design aesthetics and visual marketing.
(4) Understand platform rules.

Assessment index Click rate, silent conversion rate, bounce rate, average access time, visit depth, timely rate, degree of on-time completion, cooperation, accuracy, advertising words compliance and legitimacy, etc.

\subsubsection{Site operation}

Job responsibilities (1) Daily maintenance of store or independent stations, product launch and optimization, activity planning, and analysis of market situations.

(2) Deal with emergencies in the store.

(3) Coordinate promotion, customer service, artwork, and warehousing; make overall planning and control.

(4) Make annual, quarterly, monthly, and weekly plans; complete sales targets and implement plans.

(5) Formulate specific implementation plans, implement plans, supervise the process, and follow-up with the problems.

(6) Conduct data analysis; make weekly, monthly, or annual summary and improvement plan.

Job requirements (1) CET-4 or above; ability to communicate in English or other languages.

(2) Familiar with cross-border third-party platform operation: Data analysis, website maintenance, and product release.

(3) Sensitive to data; familiar with SEO keyword ranking and website optimization.

(4) Be able to use marketing means to promote products.

(5) Internet marketing thinking.

(6) Understand the way of thinking and lifestyle of local consumers.

Assessment index Gross sales value, click rate, conversion rate, exposure, return on investment, content quality, repurchase rate, team cooperation, presence of major mistakes, complaints, violation of platform rules, etc.

\subsubsection{Storage post}

Job responsibilities

(1) Responsible for goods preparation, inspection, loading, and delivery in the warehouse.

(2) Responsible for preparing foreign trade documents.

(3) Specific after-sales services such as goods return and exchange.

(4) Responsible for warehouse product management, classification, and input of warehouse management system

(5) Product delivery as well as product and packaging inspection.

(6) Daily inventory maintenance and management; report unsalable products.

Job requirements (1) CET-4 or above; proficient in English writing.

(2) Having business e-mail response skills.

(3) Familiar with document preparation and trade shipment process.

Assessment index Timely delivery rate, error rate, inventory accuracy rate, charge-back rate, etc. 


\section{Talent gap faced by cross-border e-commerce enterprises}

\subsection{Language-related problems}

Since cross-border trade is essentially import and export trade, language customs is a basic prerequisite. However, small and medium-sized enterprises face two problems in language customs. First, the overall English foundation of higher vocational students is weak. At present, the overall level of each student is directly proportional to his or her English level. In addition, students with better results in higher vocational colleges prefer to improve their academic qualifications rather than opting for employment after graduation; thus, students that opt for employment are those with poorer English foundation. Second, there is a lack of talents that can speak in minority languages. At present, the second language of most talents engaged in cross-border e-commerce is mainly English and there is a scarcity of talents that are well-versed in minority languages, such as German, Russian, and Spanish.

\subsection{Lack of global marketing ability}

Cross-border e-commerce enterprises are involved in businesses all around the world. They need to understand the market environment, transaction mode, culture, personal consumption habits, local customs, etc. of different countries. Most of the students who majored in International Trade, E-Commerce, and English have difficulty in accessing the aforementioned information in a systematic and in-depth manner during their education years.

\subsection{Low proficiency resulting in high training cost}

Cross-border e-commerce enterprises have raised the issue of graduates' competencies. It was acknowledged that $82.4 \%$ of fresh graduates are not really competent for the relevant posts. Fresh graduates generally lack practical experience and control over the platform rules. Their professional knowledge is not solid enough, their practical skills are weak, and their ability to solve practical problems is inadequate. At the initial stage of operation, there are often violations of platform regulations and careless behaviors that result in economic losses to enterprises, and at times, these enterprises have to halt operations. In addition, the inability to retain cross-border e-commerce talents is also one of the pain points of cross-border ecommerce enterprises. Many fresh graduates lack basic professional quality, leading to the rise of the phenomenon of resignation.

\section{Suggestions for education in view of the needs of enterprises}

\subsection{Reconstructing the teaching system according to the needs of enterprises}

With the in-depth development of cross-border e-commerce, the structure of talent demand is becoming clearer. Instead of simply adding one or two courses related to cross-border e-commerce on the basis of the original professional courses, the curriculum system of cross-border e-commerce should be reconstructed. In the teaching system, more emphasis should be on cultivating students' workplace mentality, workplace quality system, role transformation, office ability, data analysis, problem-solving skills, market control, market prediction, team management, English skills, teamwork, cross-border operation, analysis and summary ability, art design, plan formulation, customer maintenance, marketing, and other skills.

\subsection{Cultivating cross-border e-commerce teachers}

Cross-border e-commerce is a complete industrial chain, requiring the cooperation of multiple professional teachers in the training of cross-border e-commerce talents. However, many teachers lack practical experience in cross-border e-commerce in addition to its extremely fast-paced e-commerce and innovation. 
Full time teachers should participate in yearly cross-border e-commerce training and actively practice in such enterprises. In the process of training and practice, they should not only be limited to the transaction links of cross-border e-commerce platforms, but also comprehensively learn relevant knowledge in regard to the whole chain of cross-border trade.

\subsection{Exploring the integration of industry and education}

The comprehensiveness and practicality of cross-border e-commerce drive colleges and universities to constantly explore the integration of industry and education in hope to cultivate qualified cross-border ecommerce talents. It is necessary to change the original traditional teaching mode and theoretical teaching content, strengthen the cooperation between schools and enterprises, introduce real enterprise projects, carry out project-based teaching reform, establish cross-border e-commerce training bases, as well as carry out modern apprenticeship.

\section{Conclusion}

Finally, in cultivating cross-border e-commerce talents, colleges and universities should adhere to the basic goal of "skill-centered," pay attention to the needs of industrial upgrading and enterprise development, cultivate cross-border e-commerce talents with foreign language skills, e-commerce skills, and foreign trade business knowledge while understanding the concept and culture of online shopping, mastering the marketing skills of cross-border e-commerce platforms, and developing certain professional quality.

\section{Funding}

This research was supported by the Research and Discussion on Project-Based Teaching Mode of CrossBorder E-Commerce Talent Training under the Belt and Road Initiative (Project Number: JGYB201906).

\section{Disclosure statement}

The author declares that there is no conflict of interest.

\section{References}

[1] Yang J, 2018, The Internet Plus Training Mode of Cross Border Electricity Providers in Higher Vocational Colleges Is Explored. Chinese and Foreign Entrepreneurs, (24).

[2] Zhang S, 2017, Talent Demand Analysis of Cross-Border E-Commerce. Human Resource Management, (11). 